\title{
ON THE MEANING OF SOCIAL PSYCHOLOGY."
}

GOCIAL psychology in its widest sense applies to the $N$ social behavior of all animals, but more specifically, and as the term is usually employed, to the social behavior of members of the human race, both individually and collectively.

Behavior is used here in the sense in which it appears in the literature of general psychology, to point to an adjustment on the part of an organism to its environment. But not all adjustments are social, and social behavior implies those interactions or adjustments that occur among men and women and children. They may or may not be accompanied by a social consciousness. It is assumed that the interactions in question were conscious at least in their origins, excepting in cases in which they may have arisen by accident and have been discovered and made use of consciously at a later time; as for example when one discovers that one has already unwittingly adopted a mode of address which elicits favorable response from a neighbor, and therefore deliberately continues to exercise this manner of address, until it once more becomes unconscious. Social behavior, therefore, includes those automatic or relatively automatic adjustments among men-social habits-as well as conscious adjustments. Social psychology, then, is charged with accounting for the development of these so-

' The author, Mr. Robert H. Gault, is associate professor of psychology at Northwestern University and managing editor of the Journal of Criminal Law and Criminology. 
cial automatisms just as general psychology accounts for the growth of automatisms in the life of an organism.

Social psychology implies a social consciousness distinct from consciousness that is not social. By this term we mean here that aspect of human consciousness in which one takes cognizance of one's relations to others and vice versa; in which one voluntarily seeks to control another's reactions; in which one anticipates one's reaction to the behavior that may possibly be expressed in the life of another at some future time or the reactions that may occur in the reverse direction; in which one makes adjustment to an ideal that has been developed and expressed by whatever means; finally by social consciousness we mean that aspect of human consciousness in which one responds to what is "in the air," realizing all the while, even though vaguely, that one is doing so because "everybody else is doing it."

Thus we are socially conscious when we stop to consider the possible effect of our actions upon others. The student is socially conscious when in preparation for an intercollegiate debate he works in the quiet of his study week in and week out, arranging and rearranging his material with a view to getting it into such shape that it will elicit signs of approval from the audience and obtain the decision of the judges in response to his effort. The chess player is socially conscious when he anticipates his next move in case his opponent should make a certain play, or vice versa; the statesman when he anticipates the needs of the state and provides for them, as well as when, from public expressions, he realizes his error and makes correction. We are socially conscious, furthermore, when we feel constrained to adjust ourselves to an ideal. Whether we associate it with a particular person or not the ideal is personified, and in adjusting to it, or in responding in any way to its appeal, we are indirectly responding to its 
author. Thus when we are reading a book or looking at a picture we may be socially conscious. Indeed we are so if the book or the picture stimulates the vague or distinct imagery of a recognized ideal. Thus a Millet speaks to us indirectly of the nobility of common labor through an "Angelus"; a Gilbert Stuart of steadfast patriotism through the face of a Washington. When we recognize the symbolic language of the artist we are socially conscious. Finally the youth of ' $6 \mathrm{I}$ was socially conscious when he was entertaining the mental imagery of tens of thousands of other youths like himself all marching eagerly behind the fife and drum on thousands of village greens and feeling his own patriotic impulses swell in response. $\mathrm{He}$ is socially conscious when he anticipates that other boys will go out to drill if he will but do so; when he realizes that he is out because his neighbors are also. Reduced to its final terms the social consciousness is the sum total of a certain more or less defined mental imagery. We entertain in our mind's eye either anticipatory or retrospective imagery of responses to behavior, responses that might have been or that actually occurred; and this imagery seems to be aimed at the control of our behavior when we are socially conscious. It comes to fruition in the consciousness of the organism alone. It is an aspect of the total individual consciousness. It excludes the concept of an oversoul and of Urwick's super-consciousness. ${ }^{2}$ It is more than the mere consciousness of kind $^{3}$ and more than imitative consciousness, though either or both may be a part of it.

When the social consciousness of the organism has been abstracted from the total and we take stock of all that remains we find only those perceptual, ideational, and emotional experiences that come to us uncolored by any sense of their relationship to other selves than our own. The

\footnotetext{
- Urwick, Philosophy of Social Progress.

- Giddings, Elements.
} 
tree on the campus or the chair on the floor may simply mean "something there," changing or unchanging. The moment, however, at which these objects so much as suggest a plan of another intelligence than ours - a plan that arouses even a glimmering reaction of any sort on our part-at that moment the experience becomes social.

As $I$ have already intimated the social aspect of the experience may lapse according to the law of automatization. We may take the picture as a matter of course after a while and be insensitive to the message of the artist. We may develop insensitivity to the appeal of the distressed at our doors. Such a process is within the realm of social psychology just as distinctly as any other process of automatization in the field of educational psychology or elsewhere.

This social consciousness is intensified, to be sure, by the appropriate physical reaction. That is, the social consciousness of the boy of ' 61 is intensified when he marches with the rest. This is the case, at any rate, until the process of automatization is well on its way.

Social psychology is interested too in the sense of social unity that makes the whole group seem kin. It is this sense, ever present especially to those who live with others of their kind and mingle with them on intimate terms, that makes attractive a proposition that a super-consciousness or a universal sub-consciousness includes the consciousness of each one of us and that it is by dint of this background that we have our sense of social unity. The methods of psychology, however, cannot supply data concerning such a background, if indeed it exists at all.

The psychologist gets a clue to the solution of the problem of the sense of social unity from the basis of his own sense of personal identity. Here his memory and his anticipatory imagery play a large part. As each one of us retrospectively views his behavior and his psychic reac- 
tions, one of the most prominent things impressed upon him is that his life thus far has been to a great degree a series of responses to what other people have done and thought in his own immediate vicinity and even in remote regions. With the images that arise in this connection there develop associations with images anticipatory of the responses that we will make to others in imagined situations that may arise in the future; of the responses that others may make to us, and that our neighbors, near or far away, may make among themselves in certain situations. Thus it ministers to my sense of unity with my class to anticipate that a proposal coming either from me or from one of their number for the establishment of an honor system will meet with enthusiastic and honest response. My sense of social unity transcends the immediate present when through the eye of anticipation I confidently see uncounted thousands belonging to future generations modifying the conduct of their thoughts and behavior in response to ideas that are being made extant to-day by myself or by others. The sense of social unity, even the capacity for it, is a question of the mental imagery that we can command.

There are, to be sure, certain limitations upon this command of imagery. We have not met South Sea Islanders in the past and it is with some difficulty that we anticipate their responses. We cannot, therefore, have the sense of unity with them that we have with the people of our town. In other words a consciousness of kind is an essential prerequisite to the development of the sense of social unity. This sense of unity, supported or conditioned by the consciousness of kind, in agreement with the laws of automatization in general, lapses in the course of practice until finally our relations with others of our kind, in wider and wider circles, are taken for granted. Thus if we keep in mind the process of development of social behavior through con- 
sciousness to mechanism, we are in accord with DeGreef in his opinion that where people are in close contact with one another there need be no consciousness of social unity. Indeed, in such circumstances one may become so completely identified with one's neighbors as to lose social consciousness as far as one's relations with them are concerned. ${ }^{4}$

This will suggest, therefore, that social psychology, as an account of social behavior, very properly discusses the means-that is, the selection and arrangement of stimuli-by which those interactions that are appropriate to time and place may be brought about; by which, in Professor Ross's phrase, psychic "planes and currents" are established. Finally social psychology is occupied with the means by which old forms of interaction - old psychic planes and currents-are brolien up and new ones set on their way. Discovery, invention and criminality are processes that, in this connection, are fraught with meaning for social psychology.

Robert H. Gault.

Northwestern University, Evanston, Illinois.

- The point of view developed above has some points of resemblance to the argument by Prof. A. T. Ormond (Psy. Rev., VIII, 1901, p. 41) that the only way in which social intercourse is possible, or social effects producible, is through the power which each self-conscious individual has of internally representing the consciousness of his fellow. 